OPEN ACCESS

Edited by:

Luca Valentini,

University of Perugia, Italy

Reviewed by:

Debora Puglia,

University of Perugia, Italy

Loris Giorgini,

University of Bologna, Italy

*Correspondence:

Andrea Dorigato

andrea.dorigato@unitn.it

Specialty section:

This article was submitted to

Polymeric and Composite Materials,

a section of the journal

Frontiers in Materials

Received: 30 November 2018

Accepted: 05 April 2019

Published: 26 April 2019

Citation:

Dorigato A, Fredi $G$ and Pegoretti A (2019) Thermo-Mechanical Behavior

of Novel Wood

Laminae-Thermoplastic Starch Biodegradable Composites With

Thermal Energy Storage/Release

Capability. Front. Mater. 6:76

doi: 10.3389/fmats.2019.00076

\section{Thermo-Mechanical Behavior of} Novel Wood Laminae-Thermoplastic Starch Biodegradable Composites With Thermal Energy Storage/Release Capability

\author{
Andrea Dorigato*, Giulia Fredi and Alessandro Pegoretti \\ Department of Industrial Engineering and INSTM Research Unit, University of Trento, Trento, Italy
}

For the first time, multifunctional fully biodegradable composites combining structural and thermal energy storage/release capabilities were prepared and thermo-mechanically characterized. Within this scope, thin beech laminae impregnated with a phase change material (PCM) represented by poly(ethylene glycol) (PEG) were interleaved with thin foils of thermoplastic starch (TPS) and consolidated by hot pressing. From scanning electron microscopy, it was observed that a certain amount of PEG (about 11 wt\% of the total laminate) remained entrapped within the wood pores, negatively affecting the interfacial adhesion between wood laminae and TPS foils. The presence of PEG stabilized in the wood laminae was confirmed by differential scanning calorimetry tests, in which a specific melting enthalpy of $27.4 \mathrm{~J} / \mathrm{g}$ was detected with a melting peak at $55^{\circ} \mathrm{C}$. Wood permeation with PEG was responsible for an increase of the dynamic moduli $E^{\prime}$ and $E^{\prime \prime}$, as well as of the tensile and Charpy impact strength of the laminates. Therefore, this paper highlighted the possibility of developing multifunctional fully biodegradable composites capable of combining structural and thermal energy storage properties, in which the selected PCM positively contributed to the mechanical behavior of the laminates.

Keywords: starch, ultrathin wood laminae, composites, poly(ethylene glycol), energy storage

\section{INTRODUCTION}

It is well-known that interest in fiber reinforced polymers (FRPs) has noticeably grown over the last decades (Gay et al., 2003), mostly because of their elevated specific mechanical performance, easy processability and corrosion resistance. On the other hand, various environmental concerns have arisen regarding the use of traditional reinforcing fibers (such as glass, carbon and aramid) in FRPs (Pegoretti, 2007) as life cycle assessments on these materials have evidenced their limits in terms of recyclability and final disposal operations (Dorigato and Pegoretti, 2012). A partial solution to these concerns could be represented by the use of natural fibers (i.e., kenaf, hemp, flax, cellulose, etc.) as reinforcement of both thermoplastic and thermosetting matrices (Wu, 2009). However, even though with these fibers it is possible to reach most of the physical properties of conventional laminates (García et al., 2008; Iwatake et al., 2008; Kunanopparat et al., 2008), it is very difficult from a technological point of view to perform efficient thermo-mechanical recycling of these materials because of the limited thermal degradation resistance of natural reinforcements 
(Houshyar and Shanks, 2003). In this sense, a possible solution to these environmental issues could be represented by the development of fully biodegradable composites, in which both the constituents (i.e., the matrix and the reinforcing phase) can be degraded under certain environmental conditions.

Among the natural reinforcements that can be used for the production of fully biodegradable composites, wood fibers represent one of the most interesting options (Bledzki et al., 2002). Wood is mainly constituted by carbon, hydrogen and oxygen in the form of cellulose (40-50 wt\%), hemicellulose (20 wt\%), lignin (about $35 \mathrm{wt} \%$ ) and pectic substances in limited concentrations (Core et al., 1979). From a mechanical point of view, wood behaves like a heterogeneous anisotropic material. Moreover, in the low deformation regime it can be considered as an orthotropic material (Green et al., 1999), and its mechanical performance is strongly influenced by the presence of nodes and microstructural defects. Moreover, considering that wood can absorb up to 25-30 wt\% of water, the environmental conditions strongly affect the mechanical response of woodbased materials.

From a microstructural point of view, the cross section of wood-based materials is formed by a regular distribution of cellular lumen with isolated and clustered pores and thick-walled fibers. In the case of beech, large parenchymal rays are generally distended along growth ring boundaries, while the concentration of gum inclusions, salt crystals or lattices is rather limited (Giordano, 1981). In the last years, particular scientific and technological attention was given to wood plastic composites (WPCs), constituted by wood fibers or wood flour compounded with thermoplastic matrices, such as polypropylene (PP), polyethylene (PE), and polyvinylchloride (PVC) (Oksman and Sain, 2008). These materials can be processed through the traditional technologies of thermoplastics (i.e., extrusion, injection molding). However, the mechanical properties of WPCs are generally considerably poorer than those of structural wood components, even at elevated filler amounts, especially under severe environmental conditions (Srimalanon et al., 2016). Quite surprisingly, the possibility to utilize thin wood laminae to develop novel thermoplastic wood composites laminates did not receive much attention in the open literature.

Among biodegradable matrices that could be potentially applied in fully biodegradable composite laminates, thermoplastic starch (TPS) has recently drawn considerable attention. From the chemical point of view, starch is a polysaccharide with a semicrystalline structure, composed by linear amylose and highly branched amylopectin (Bogracheva et al., 2002), and it can be processed through extrusion and injection molding. In order to overcome the problems related to its elevated hydrophilicity, some attempts were made to modify the TPS chemical structure through acetylation (Chi et al., 2008; Ayucitra, 2012) or upon blending with other biopolymers, such as polycaprolactone (PCL) and polyhydroxybutyrate-co-valerate (PHBV) (Averous et al., 2000), or with synthetic plastics, like polyethylene. The most widespread TPS-based products are commercially known as Mater-Bi ${ }^{\circledR}$ (Novamont, Italy) (Bastioli, 1997) and Bioplast ${ }^{\circledR}$ (Biotec, Germany) (Lorcks, 1998).
Two examples of biodegradable laminates have been recently developed by our group. In the first case, polyvinyl alcohol (PVOH)-based composites were prepared by a hand layup procedure, impregnating ultrathin beech laminae with an aqueous solution of PVOH (Dorigato et al., 2018b), while in a second paper thermoplastic composites reinforced with wood laminae were produced through a hot-pressing process by using thermoplastic starch foils (Dorigato et al., 2018a). In both of these papers, it was found that the resulting materials were characterized by a peculiar microstructure, in which the porosity of the beech laminae was occluded by the polymer matrix. The consequence of the matrix permeation within the wood pores was that the resulting laminates showed higher elastic modulus and tensile strength with respect to their constituents.

It is challenging to impart also multifunctional properties to fully biodegradable composites. In fact, the scientific and industrial interest toward materials able to combine different properties (structural, electrical, magnetic, thermal, etc.) has strongly increased in the latest years (Gibson, 2010). In this scenario, polymer-matrix composites are particularly suitable to be designed as multifunctional materials (Salonitis et al., 2010) because they combine the peculiar properties of polymers, such as the low density, good processability and cheapness, with the elevated stiffness and strength of the reinforcing fibers (Mallick, 2007). According to the authors' opinion, one of the most interesting options could be to prepare fully biodegradable laminates with thermal energy storage (TES) capability. In fact, TES technology is based on the storage of heat and its release when needed, thus reducing the gap between thermal energy availability and request (Pielichowska and Pielichowski, 2014). Therefore, TES systems can be utilized to accumulate excess or waste heat, like in solar thermal power plants, to recover waste industrial heat (Khadiran et al., 2015), to control the temperature inside the buildings (Onder et al., 2008), in smart textiles for body temperature regulation (Sobolciak et al., 2016), or in the cooling systems for electronic devices (Luyt and Krupa, 2009). Multifunctional composites combining good mechanical properties and TES capability could thus be applied were weight and volume saving requirements should be coupled with energy storage capability and/or temperature control operations (Rigotti et al., 2018). TES systems are generally classified depending on the underlying process in sensible, thermochemical, or latent heat-storage systems. Among them, phase change materials (PCMs) undergo an endo/exothermic solid-solid or solid-liquid transition, and can be classified as organic, inorganic or eutectic (Sari et al., 2005). Thanks to their elevated specific phase change enthalpy, narrow transition temperature interval, limited supercooling, lightness and cheapness, organic PCMs, i.e., paraffins, poly(ethylene glycol) (PEG) and fatty acids, are probably the most widely diffused (Dorigato et al., 2017; Fredi et al., 2017). In particular, PEG is a versatile and biodegradable PCM with elevated melting enthalpy, tunable transition temperature range, elevated thermal stability, good biocompatibility, non-toxicity and noncorrosiveness (Sundararajan et al., 2016; Kou et al., 2019). Because of these peculiar properties, researchers have recently put much efforts to synthesize novel PCMs based on PEG, trying to 
physically blend PEG with other supporting materials, to perform chemical modifications to prepare PEG based solid/solid PCMs or to impregnate PEG in porous materials (Wang et al., 2016; Yang et al., 2016; Zhou et al., 2018). Nowadays, most of the studies on PEG-based PCMs are focused on the preparation of novel PCMs with improved thermal energy storage capability. The problems associated with the poor thermal conductivity of organic PCMs and their need to be confined to limit their leakage at the molten state (Kastiukas et al., 2016) could be partially solved through their encapsulation in organic or inorganic shells (Ozaki et al., 2008), or upon the shape stabilization in a polymer matrix (Yoo et al., 2016), in a layered/porous structure or in a nanostructured filler (Alexandre et al., 2009). Moreover, the use of a conductive nanofiller could also improve the thermal conductivity of the resulting systems. Due to its porous microstructure, it is possible to hypothesize that wood could also be an interesting candidate for the shape stabilization of organic PCMs at the molten state.

Quite interestingly, only a few investigations have been performed on the possibility of preparing multifunctional PMCs combining TES and structural features. For example, our group recently developed novel epoxy/carbon fiber composites containing carbon nanotube (CNT)-stabilized paraffinic wax (Fredi et al., 2017, 2018a), epoxy/discontinuos carbon fibers with microencapsulated paraffin (Dorigato et al., 2019), thermoplastic polyamide 12 (PA12)/glass fiber composites containing both microencapsulated and shape stabilized PCMs, reinforced with long glass fibers (Fredi et al., 2018a) or with discontinuous carbon fibers (Dorigato et al., 2018c; Fredi et al., 2019), or thermoplastic acrylic Elium ${ }^{\circledR} /$ carbon fiber laminates containing microencapsulated paraffin (Fredi et al., in preparation). However, no papers on the production of fully biodegradable composites with good mechanical properties and TES capability can be found in the open literature. On the basis of these considerations, the aim of the present paper is to develop for the first time multifunctional fully biodegradable composite laminates, constituted by a thermoplastic starch matrix reinforced with thin wood laminae, in which the thermal energy storage function can be obtained by impregnating wood laminae with PEG in the molten state. The microstructural, thermal and mechanical behavior of the resulting laminates was investigated, considering also the effect of the orientation of the reinforcing phase within the composites. The properties of the resulting laminates were also compared with those of their constituents.

\section{EXPERIMENTAL}

\section{Materials}

Thermoplastic starch MaterBi ${ }^{\circledR}$ EF51V was supplied by Novamont Spa (Novara, Italy) in the form of foils with a thickness of $100 \mu \mathrm{m}$. This TPS grade is characterized by a density of 1.2 $\mathrm{g} / \mathrm{cm}^{3}$, a MFI of $4 \mathrm{~g} / 10 \mathrm{~min}\left(190^{\circ} \mathrm{C}, 2.16 \mathrm{~kg}\right)$ and a melting temperature of $167^{\circ} \mathrm{C}$.

The employed poly(ethylene glycol) was PEG 2000 purchased by Alfa Aesar (Karlsruhe, Germany). It has a molecular weight of $1,800-2,200 \mathrm{~g} / \mathrm{mol}$ and a melting temperature of $51-55^{\circ} \mathrm{C}$, according to the producer's datasheet.

For the preparation of the thin wood laminae (Figure 1A), a beech plant with a density of about $0.73 \mathrm{~g} / \mathrm{cm}^{3}$ if conditioned at $23^{\circ} \mathrm{C}$ and a relative humidity of $50 \%$ was selected. The selection of this wood species is motivated by its regular morphology and anatomical structure, as described in the Introduction. Thin wood laminae, with a thickness of about $320 \mu \mathrm{m}$, were kindly provided by the CNR Ivalsa Institute (San Michele all' Adige,

A

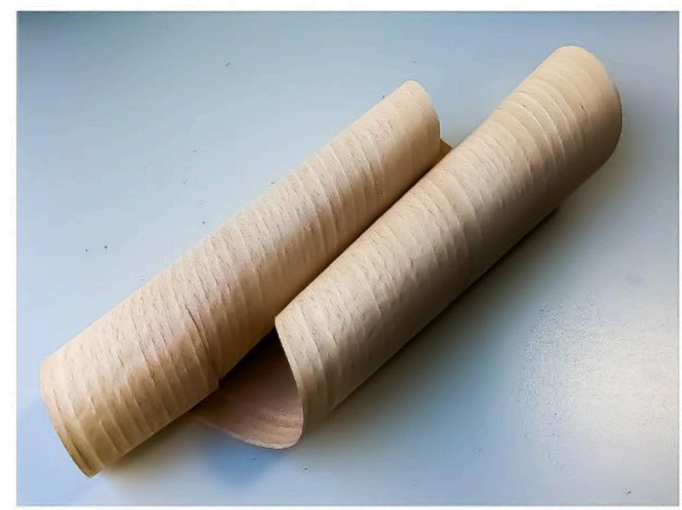

B

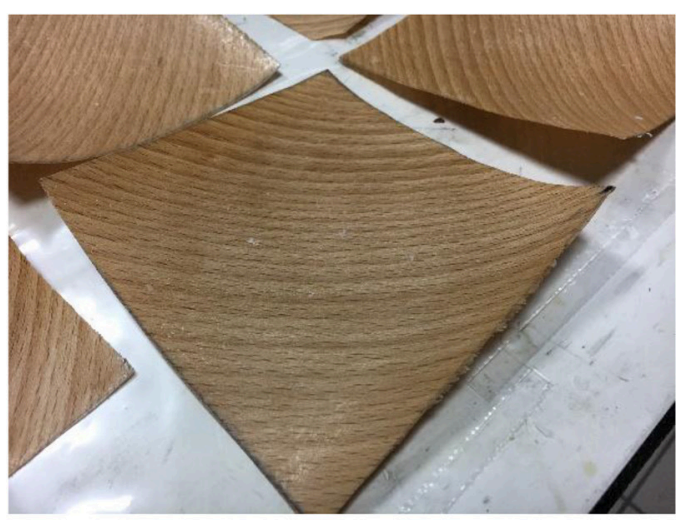

C

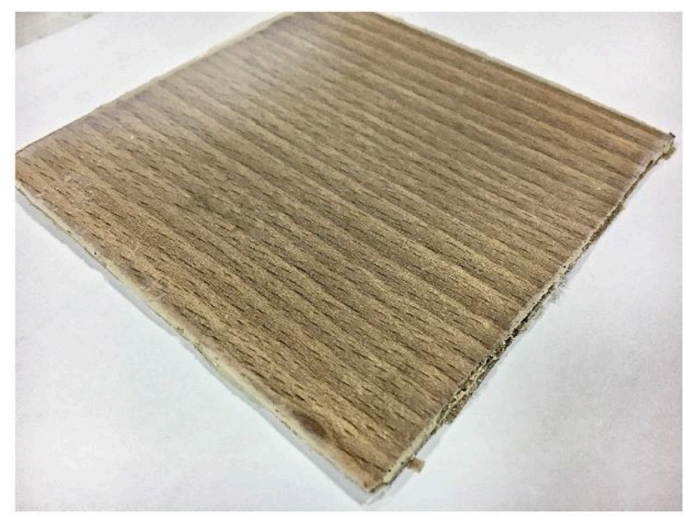

FIGURE 1 | Representative images of (A) neat wood lamina; (B) wood laminae after PEG impregnation; (C) wood/PEG/starch laminate. 
Italy). The laminae were obtained through a Marunaka Super Meca-s planer (Marunaka Tekkosho Inc., Shizuoka, Japan) from beech boards, conditioned at a temperature of $23^{\circ} \mathrm{C}$ and a relative humidity of $50 \%$. Although this machine allows the production of even thinner laminae, the choice of the thickness was motivated by the need to reach a compromise between the flexibility of the thinner laminae and their PEG storage capability.

\section{Preparation of the Samples}

Wood laminae were cut in square sheets of $120 \times 120 \mathrm{~mm}^{2}$, with the wood fibers oriented either parallel or at $45^{\circ}$ with respect to the square edge. The sheets were immersed in the molten PEG at $70^{\circ} \mathrm{C}$ for $5 \mathrm{~min}$, then taken out and immediately gently blotted with absorbent paper to remove excess molten PEG from the surface (Figure 1B). Each wood lamina was weighed before and after immersion in liquid PEG in order to measure the weight fraction of absorbed PEG. Preliminary experiments had shown that a soaking time of $5 \mathrm{~min}$ was enough to reach the maximum weight increase due to PEG absorption, as a longer soaking time (up to $24 \mathrm{~h}$ ) did not result in a greater weight increase. The wood/PEG laminae were interleaved with starch foils of $120 \times 120 \mathrm{~mm}^{2}$ and compacted in a hot-plate press at $170^{\circ} \mathrm{C}$ for $7 \mathrm{~min}$, with an applied pressure of $1 \mathrm{MPa}$. Each laminate (Figure 1C) consisted of 5 wood/PEG laminae interleaved with 6 starch sheets. The samples were produced following two stacking sequences, i.e., $\left[0_{5}\right]$ (unidirectional) and [+45/-45/+45/-45/+45] (angle ply). Laminates with virgin wood laminae (without PEG impregnation) were also prepared for comparison. Moreover, the mass of each constituent of each laminate was measured before the hot-pressing stage and compared to the final mass of the prepared laminates to study the PEG leakage during the laminate preparation. Specimens with different orientations were cut out of the prepared laminates for the subsequent characterization. The characterization was performed also on the constituents, i.e., the starch foils, the virgin wood laminae and the PEG-impregnated laminae. The list of the prepared samples is reported in Table 1. All the composite laminates with their relative constituents were stored at $23^{\circ} \mathrm{C}$ with a relative humidity of $50 \%$. It was decided to condition both the constituents and the laminates at this temperature and humidity level because these are the typical hygrothermal conditions of the laboratory. In this way, the influence of the temperature and of the moisture absorption during the lab tests could be minimized. It could be also interesting to point out that this production process, which consists of embedding the PCM directly in the reinforcing phase and employing matrix foils, allows the preparation of thermoplastic laminates without a melt compounding step, which could partially degrade the PCM (Fredi et al., 2018a). Therefore, the pristine thermal energy storage properties of PEG should be retained.

\section{Experimental Techniques}

The microstructural features of the prepared samples were investigated through a scanning electron microscope (SEM) Jeol IT300, operating at an acceleration voltage of $15 \mathrm{kV}$. The samples F, FP, FA, and LAM were cryofractured in liquid nitrogen, and the fracture surface was analyzed after Pt-Pd sputtering.
TABLE 1 | List of the prepared samples.

\begin{tabular}{|c|c|c|}
\hline $\begin{array}{l}\text { Sample } \\
\text { acronym }\end{array}$ & $\begin{array}{l}\text { Description of } \\
\text { the constituents }\end{array}$ & $\begin{array}{l}\text { Wood fiber } \\
\text { orientation }\end{array}$ \\
\hline $\mathrm{F}-\mathrm{L}$ & Single wood lamina & Longitudinal \\
\hline$F-T$ & Single wood lamina & Transversal \\
\hline PEG & Poly(ethylene glycol) & - \\
\hline A & Single starch foil & - \\
\hline FP-L & $\begin{array}{l}\text { Single wood lamina impregnated with } \\
\text { PEG }\end{array}$ & Longitudinal \\
\hline FP-T & $\begin{array}{l}\text { Single wood lamina impregnated with } \\
\text { PEG }\end{array}$ & Transversal \\
\hline FA-L & 5 wood laminae and 6 starch foils & Unidirectional (long.) \\
\hline FA-T & 5 wood laminae and 6 starch foils & Unidirectional (transv.) \\
\hline FA-O & 5 wood laminae and 6 starch foils & Angle ply \\
\hline LAM-L & $\begin{array}{l}5 \text { wood laminae impregnated with PEG } \\
\text { and } 6 \text { starch foils }\end{array}$ & Unidirectional (long.) \\
\hline LAM-T & $\begin{array}{l}5 \text { wood laminae impregnated with PEG } \\
\text { and } 6 \text { starch foils }\end{array}$ & Unidirectional (transv.) \\
\hline LAM-O & $\begin{array}{l}5 \text { wood laminae impregnated with PEG } \\
\text { and } 6 \text { starch foils }\end{array}$ & Angle ply \\
\hline
\end{tabular}

Thermogravimetric analysis (TGA) was performed through a TA Q5000 IR thermobalance. The test was performed on the constituents (A, F and PEG), on the PEG-impregnated wood lamina (FP) and on both the prepared laminate types (FA and LAM). Specimens of $\sim 20 \mathrm{mg}$ were cut out of all the prepared samples and tested at $10^{\circ} \mathrm{C} / \mathrm{min}$ up to $700^{\circ} \mathrm{C}$, under a nitrogen flow of $150 \mathrm{ml} / \mathrm{min}$. These tests allowed the measurement of the temperatures corresponding to a mass loss of $1 \mathrm{wt} \%\left(\mathrm{~T}_{1 \%}\right)$ and $5 \mathrm{wt} \%\left(\mathrm{~T}_{5 \%}\right)$, the temperature corresponding to the initial stages of degradation $\left(\mathrm{T}_{\text {onset }}\right)$, determined with the tangent method, the peak temperature of the mass loss derivative $\left(\mathrm{T}_{\mathrm{d}}\right)$, indicating the maximum degradation kinetics, the initial mass loss before $\mathrm{T}_{\text {onset }}$ $\left(\mathrm{m}_{\mathrm{i}}\right)$ and the residual mass after the test $\left(\mathrm{m}_{\mathrm{r}}\right)$.

Differential scanning calorimetry (DSC) was performed with a Mettler DSC30 instrument. The test was performed on the constituents (A, F, and PEG), on the PEG-impregnated wood lamina (FP) and on both the prepared laminate types (FA and LAM). Specimens of $\sim 10 \mathrm{mg}$ were cut out of all the prepared samples and tested at $10^{\circ} \mathrm{C} / \mathrm{min}$ in the temperature interval between -20 and $100^{\circ} \mathrm{C}$, under a nitrogen flow of $100 \mathrm{ml} / \mathrm{min}$. All the specimens were subjected to a first heating scan, a cooling scan and a second heating scan. In this way, the melting and crystallization temperatures $\left(\mathrm{T}_{\mathrm{m}}, \mathrm{T}_{\mathrm{c}}\right)$ and enthalpy $\left(\Delta \mathrm{H}_{\mathrm{m}}, \Delta \mathrm{H}_{\mathrm{c}}\right)$ of the PEG and of the starch phases were determined. An effective weight fraction of PEG inside the laminates was then calculated from the measured phase change enthalpy. The test also evidenced the presence of irreversible phenomena, such as the evaporation of the absorbed water.

The viscoelastic properties of the samples were investigated through dynamic-mechanical analysis (DMA), by using a DMAQ800 machine, provided by TA Instruments (New Castle, DE, USA). The test was performed in tensile mode, between 0 and $150^{\circ} \mathrm{C}$ at $3^{\circ} \mathrm{C} / \mathrm{min}$, with a maximum deformation of $0.05 \%$ applied at a frequency of $1 \mathrm{~Hz}$. The test was performed on the 
TABLE 2 | Mass and weight fraction of the constituents of the sample FP and the two laminates (FA and LAM).

\begin{tabular}{|c|c|c|c|c|}
\hline Sample & Constituent & Mass (g) & Nominal weight fraction (\%) & Experimental total weight (g) \\
\hline \multirow[t]{2}{*}{ FP } & $F($ wood) & $2.9 \pm 0.1$ & $53 \pm 6$ & $5.4 \pm 0.5$ \\
\hline & PEG & $2.5 \pm 0.4$ & $46 \pm 11$ & \\
\hline \multirow[t]{2}{*}{ FA } & A (starch) & $10.1 \pm 0.3$ & $41 \pm 2$ & $24.3 \pm 0.9$ \\
\hline & $F($ wood $)$ & $14.6 \pm 0.6$ & $59 \pm 3$ & \\
\hline \multirow[t]{3}{*}{ LAM } & A (starch) & $10.1 \pm 0.3$ & $27 \pm 2$ & $28.2 \pm 0.8$ \\
\hline & $\mathrm{F}$ (wood) & $14.6 \pm 0.6$ & $39 \pm 3$ & \\
\hline & PEG & $12 \pm 2$ & $34 \pm 5$ & \\
\hline
\end{tabular}

samples F, A, FP, FA and LAM, in the $\mathrm{L}$ and T directions (where applicable), on rectangular specimens with dimension of $25 \times 5$ $\mathrm{mm}^{2}$, while the thickness was that of each sample.

Quasi-static tensile tests were performed with a universal dynamometer Instron 5969, equipped with a $50 \mathrm{kN}$ load cell, according to ISO 527 standard. Rectangular specimens with inplane dimensions of $120 \times 10 \mathrm{~mm}^{2}$ were cut from the samples F, A, FP, FA, and LAM and tested at $5 \mathrm{~mm} / \mathrm{min}$ until failure. The samples FA and LAM were tested in L, T and O directions, while the samples $\mathrm{F}$ and FP were tested in the $\mathrm{L}$ and $\mathrm{T}$ directions. Five specimens were tested for each sample and for each considered direction. The stress-strain curves allowed the determination of the tensile strength $\left(\sigma_{b}\right)$, and of the strain at break $\left(\varepsilon_{b}\right)$. While testing the wood laminae with and without PEG (samples F and FP), small plywood blocks were interposed between the specimen and the grips to avoid damaging the sample due to the contact with the hard steel grips. For the samples LAM and FA, five additional specimens for each of the considered directions ( $\mathrm{L}, \mathrm{T}$, O) were tested at $0.25 \mathrm{~mm} / \mathrm{min}$ for the measurement of the elastic modulus by using a resistance extensometer Instron 2620 with a gauge length of $12.5 \mathrm{~mm}$. The elastic modulus was measured as the secant modulus of the stress/strain curves between the strain values of $0.05 \%$ and $0.25 \%$. The elastic modulus was calculated in the same way also on the stress-strain curve of the other specimens.

Finally, Charpy impact tests were performed on the samples FA and LAM in the L and T directions, by using a Ceast 6549 impactor equipped with a hammer with an arm length of about $25 \mathrm{~cm}$ and a mass of $0.48 \mathrm{~kg}$, positioned at a starting angle of $150^{\circ}$. In this way, the tests were performed at an impact speed of 2.9 $\mathrm{m} / \mathrm{s}$, with a maximum impact energy of $2 \mathrm{~J}$. A thin plasticine layer was used to damp the vibrations to avoid the inertial peak in the force-displacement signal. Tests were performed on rectangular specimens having nominal dimensions of $120 \times 10 \times 2 \mathrm{~mm}^{3}$, with a span length of $40 \mathrm{~mm}$. At least five specimens were tested for each sample. In this way, the values of maximum force $\left(F_{b}\right)$ and of the specific energy absorbed under impact conditions $\left(\mathrm{U}_{\mathrm{sp}}\right)$ were determined.

\section{RESULTS AND DISCUSSION}

Table 2 reports the weight composition of a single wood lamina impregnated with PEG (FP) as well as the nominal mass of each component before the hot-pressing step and the nominal weight composition for each laminate (FA and LAM). It can be observed that the quantity of PEG absorbed by a single lamina is $~ 86 \mathrm{wt} \%$ of its initial mass. On the other hand, if five of these laminae are alternated to 6 starch foils, the experimental mass of the laminate obtained through hot-pressing (LAM) is $\sim 25 \mathrm{wt} \%$ lower than the sum of its components. This mass loss can be almost entirely attributed to the leakage of PEG out of the wood laminae, as the mass loss of the laminate without PEG (FA) is almost negligible. Therefore, the effective PEG weight fraction in the laminate is $\sim 11 \mathrm{wt} \%$. This leakage suggests that a considerable fraction of the absorbed PEG has just solidified on the surface of the laminae and is not properly confined in the wood porosity, and the gentle blotting is not sufficient to remove excess PEG. However, the major part of PEG was successfully stabilized into the wood laminae.

Figures 2A-F shows the SEM micrographs of the cryofracture surface of the prepared samples. Since the cross section was investigated with this technique, in the samples with longitudinal fibers (L) the wood fibers are perpendicular to the fracture plane, while they are parallel in the samples with transversal fibers (T). In Figures 2A,B FESEM micrographs of the wood laminae cut in the transversal and in the longitudinal direction are respectively reported. As already shown in our previous papers on ultra-thin wood laminae impregnated with poly(vinyl alcohol) (Dorigato et al., 2018b), in the longitudinal direction the peculiar structure of the wood can be appreciated, with tracheids, wood fibers and vessels, while the parenchymal cells are less clearly visible. Tracheids and wood fibers are characterized by a mean diameter of about $10 \mu \mathrm{m}$, while wood vessels present an average size of $40 \mu \mathrm{m}$. The presence of some tracheids in radial direction can be appreciated in the transversal section. From the micrographs of the laminae impregnated with PEG (Figures 2C,D), it can be observed that PEG partially fills the wood porosity. This could be explained by assuming that the volume fraction of the closed porosity is not negligible. Moreover, the viscosity of the molten PEG is too high to allow the smallest pores to be filled in the time window of the impregnation process (up to $24 \mathrm{~h}$ ). Moreover, the surface of the lamina hosts a considerable amount of PEG, as suggested by the smoothness of the surfaces of the laminae containing PEG (indicated by arrows), if compared to the remarkably rough surfaces of the neat wood laminae. This may complicate the adhesion between the wood laminae and the starch matrix, an issue partially visible from the fracture surface of the two laminates 

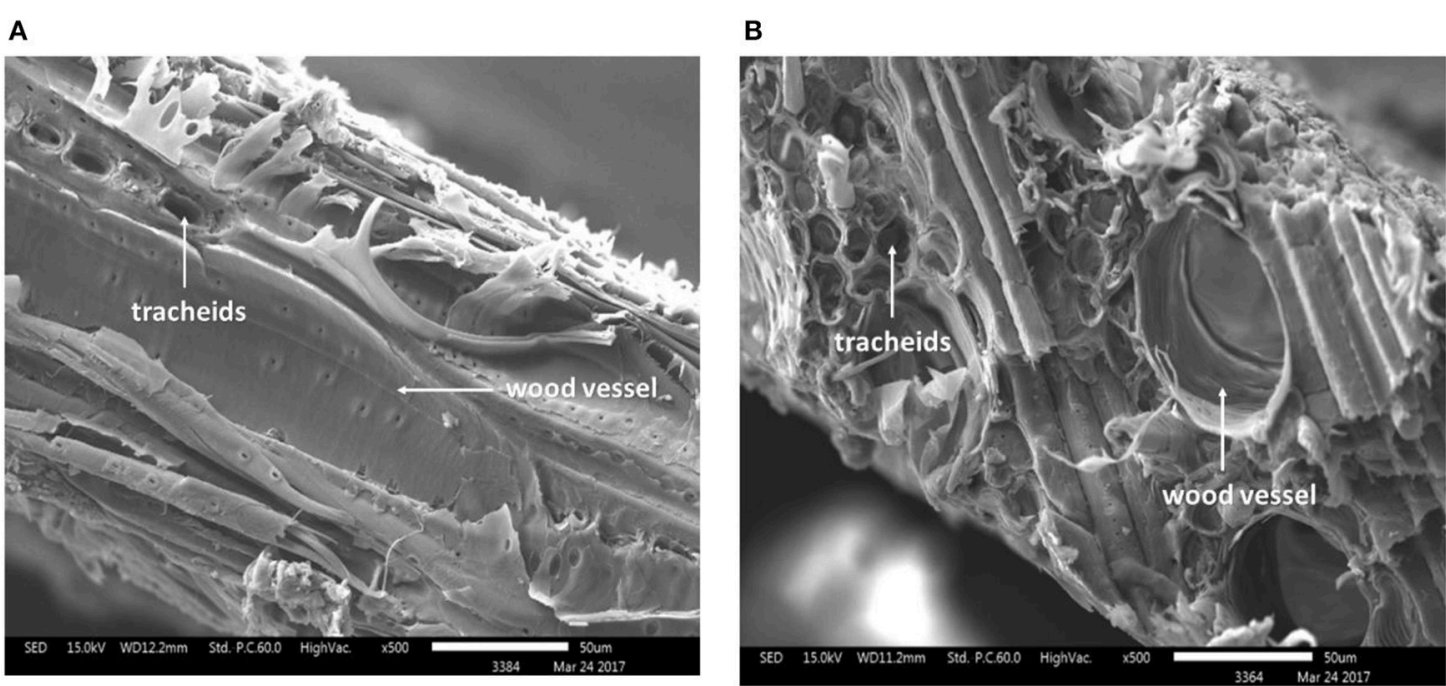

C

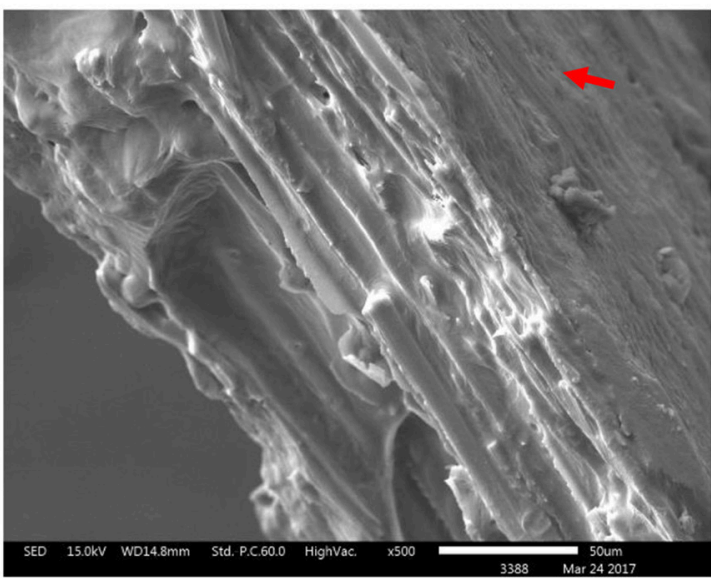

E

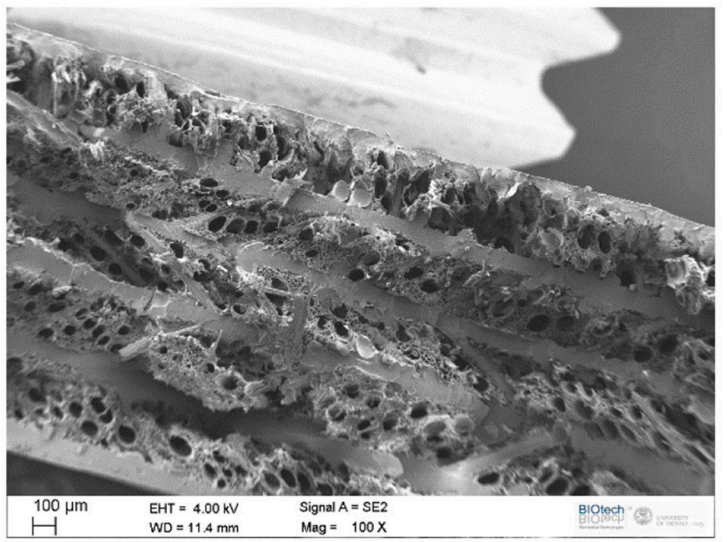

D

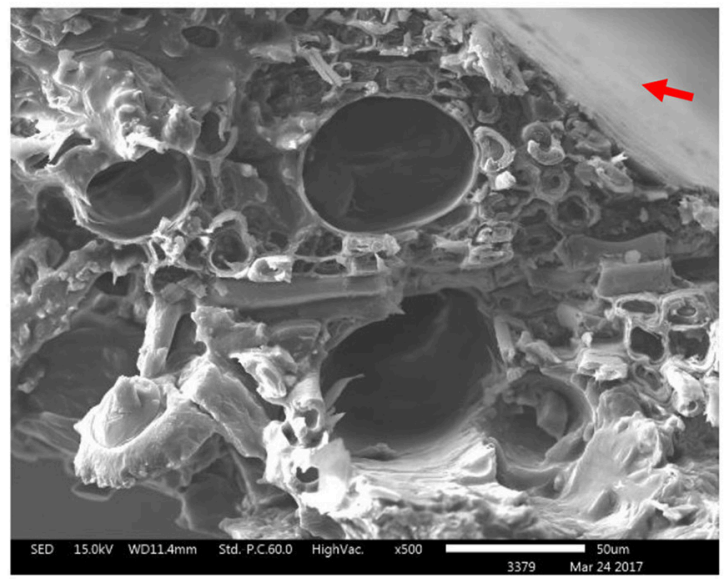

$\mathbf{F}$

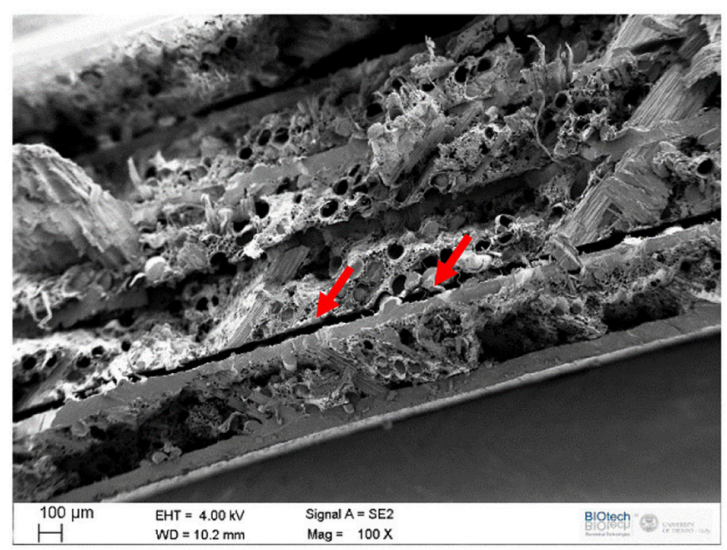

FIGURE 2 | SEM micrographs of the cryofracture surface (cross-section) of the prepared samples. (A) F-T; (B) F-L; (C) FP-T; (D) FP-L; (E) FA-T; (F) LAM-T.

(Figures 2E,F). In the laminate containing PEG (Figure 2F) the interlaminar adhesion seems worse than that of the neat laminate, as the cryofracturing operations caused delamination (indicated by the arrow), which is not observed in the neat laminate. However, this apparent worsening in the interlaminar adhesion due to the PCM does not negatively affect the mechanical 
TABLE 3 | Results of the TGA tests on the prepared samples.

\begin{tabular}{lcccccc}
\hline Sample & $\mathbf{T}_{\mathbf{1} \%}\left({ }^{\circ} \mathbf{C}\right)$ & $\mathbf{T}_{\mathbf{5} \%}\left({ }^{\circ} \mathbf{C}\right)$ & $\mathbf{T}_{\mathbf{d}}\left({ }^{\circ} \mathbf{C}\right)$ & $\mathbf{T}_{\text {onset }}\left({ }^{\circ} \mathbf{C}\right)$ & $\mathbf{m}_{\mathbf{i}}(\%)$ & $\mathbf{m}_{\mathbf{r}}(\%)$ \\
\hline F & 53.0 & 241.3 & 345.0 & 263.0 & 5.76 & 0.38 \\
PEG & 208.4 & 274.5 & 396.9 & 352.4 & 0.00 & 0.00 \\
A & 281.3 & 316.0 & 400.0 & 316.8 & 0.00 & 0.00 \\
FP & 89.3 & 265.4 & 405.1 & 317.8 & 2.01 & 0.04 \\
LAM & 29.4 & 260.7 & 365.5 & 293.5 & 2.04 & 0.27 \\
\hline
\end{tabular}

$T_{1 \%}, T_{5 \%}=$ temperature corresponding to a mass loss of 1 and $5 \mathrm{wt} \%$.

$T_{d}=$ temperature corresponding to the maximum degradation rate (peak of the mass loss derivative signal).

$T_{\text {onset }}=$ temperature corresponding to the initial stages of degradation, after the water evaporation.

$m_{i}=$ initial mass loss before $T_{\text {onset }}$

$m_{r}=$ residual mass after the test .

and impact properties, as reported hereafter. In future works on these systems it could be important to perform a detailed characterization of the interlaminar adhesion conditions of the prepared composites, as the interlaminar fracture toughness is one of the key aspects in the assessment of the mechanical behavior of composite materials.

TGA analysis was performed to evaluate the resistance to the thermal degradation of the laminates and of each constituent. Figure 3 shows the TGA thermograms (with the residual mass and the derivative of the mass loss) of the sample LAM and of its three constituents, i.e., PEG, F, and A, while Table 3 reports also the results on the sample FP. For the sample $\mathrm{F}$, the initial mass loss $\left(\mathrm{m}_{\mathrm{i}}\right)$ of $\sim 5.8 \%$ is imputable to the absorbed water. This behavior is also observed in the samples FP and LAM, but to a lesser extent, as for these samples the wood laminae are only a fraction of the total mass. After water evaporation, the thermal degradation of the wood phase becomes appreciable above $250^{\circ} \mathrm{C}$ and occurs in two main steps. Conversely, no water was detected on the samples A and PEG, which indicates that the total water fraction of the composites is entirely absorbed by the wooden phase. The thermal degradation of these two polymer phases starts to be evident at 320$350^{\circ} \mathrm{C}$ and reaches the maximum rate at $\sim 400^{\circ} \mathrm{C}$. From these results, it can be concluded that the thermal stability of all the constituents is sufficient to withstand the processing temperature of $170^{\circ} \mathrm{C}$. Moreover, as expected, the degradation thermogram of the sample FP lies between those of its constituents, i.e., F and PEG. Also, the thermal degradation of the sample LAM shows all the degradation steps of its constituents, as it can be better appreciated from the mass loss derivative signal. From TGA/DTG thermograms reported in Figure 3, it is also evident that the degradation of PEG and A samples is almost complete at $500^{\circ} \mathrm{C}$, while the $\mathrm{F}$ and LAM samples present a last degradation step between 500 and $550^{\circ} \mathrm{C}$, probably due to the degradation of some wood constituents in inert atmosphere. A detailed analysis of this degradation stage, which occurs far above the application temperature interval of the prepared laminates, is out of the scope of this work, and it could be better investigated in the future developments of this work. However, as reported in Table 3, the residual mass values at $700^{\circ} \mathrm{C}\left(\mathrm{m}_{\mathrm{r}}\right)$ are below $0.4 \%$ for all the samples, meaning that all the tested

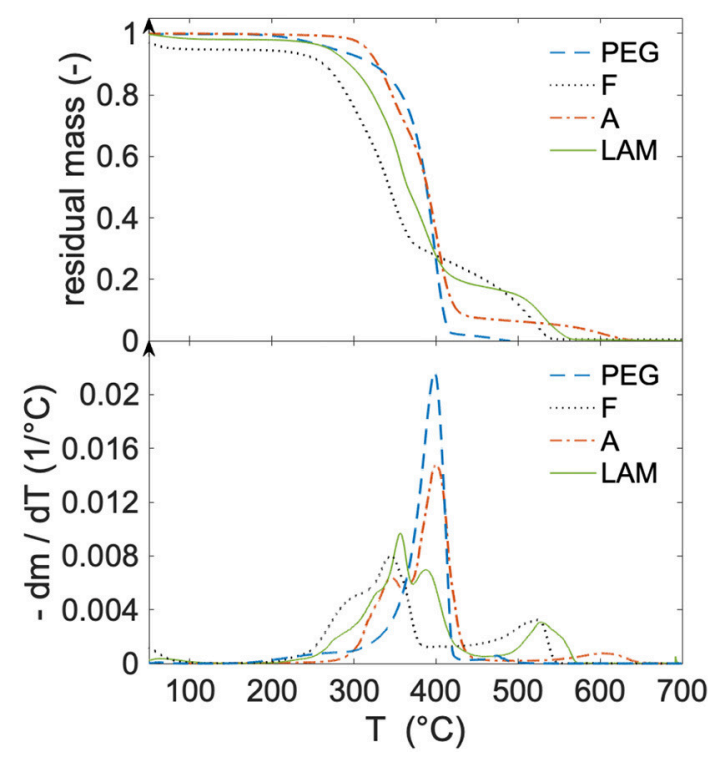

FIGURE 3 | Results of the TGA tests on the samples F, A, PEG, and LAM: residual mass and mass loss derivative as a function of temperature.

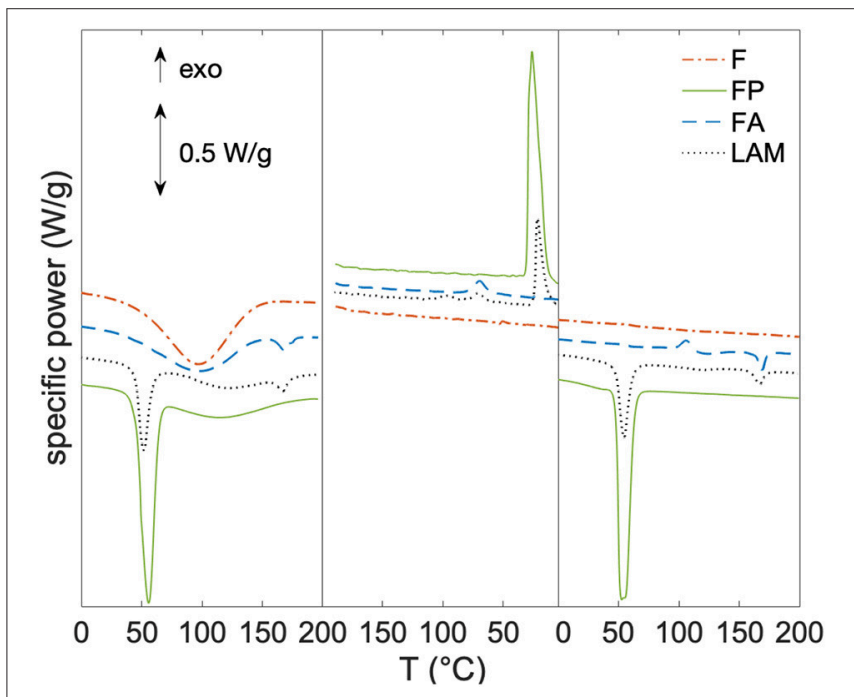

FIGURE 4 | DSC thermograms of the prepared laminates, showing the three scans (first heating, cooling, second heating). Samples F, FP, FA, and LAM.

materials underwent a complete thermal degradation even in inert atmosphere.

The DSC tests were performed to investigate the thermal transitions of the constituents and to assess the thermal energy storage capability of the PEG within the laminates. In fact, as reported in many papers in the literature, DSC is the most useful technique to assess the TES capability of these materials (Pielichowska and Pielichowski, 2014). In the present paper, this test allowed the determination of the melting (and crystallization) enthalpy values of the PEG phase within the laminates. The DSC thermograms of the prepared samples are reported in Figure 4, 
TABLE 4 | Results of the DSC tests on the prepared samples (first heating scan and cooling scan).

\begin{tabular}{|c|c|c|c|c|c|c|c|c|}
\hline Sample & $\mathrm{T}_{\mathrm{m}}^{\mathrm{PEG}}\left({ }^{\circ} \mathrm{C}\right)$ & $\Delta H_{\mathrm{m}}^{\mathrm{PEG}}(\mathrm{J} / \mathrm{g})$ & $\mathrm{T}_{\mathrm{C}}^{\mathrm{PEG}}\left({ }^{\circ} \mathrm{C}\right)$ & $\Delta H_{c}^{P E G}(J / g)$ & $\mathrm{T}_{\mathrm{m}}^{\mathrm{A}}\left({ }^{\circ} \mathrm{C}\right)$ & $\Delta H_{\mathrm{m}}^{\mathrm{A}}(\mathrm{J} / \mathrm{g})$ & $\mathrm{T}_{\mathrm{C}}^{\mathrm{A}}\left({ }^{\circ} \mathrm{C}\right)$ & $\Delta H_{c}^{A}(J / g)$ \\
\hline PEG & 52.6 & 168.9 & 30.9 & 155.3 & - & - & - & - \\
\hline$A$ & - & - & - & - & 168.1 & 9.8 & 71.1 & 10.1 \\
\hline FP & 56.1 & 88.5 & 25.8 & 86.7 & - & - & - & - \\
\hline FA & - & - & - & - & 168.7 & 4.6 & 70.9 & 5.1 \\
\hline LAM & 54.7 & 27.4 & 21.5 & 24.1 & 166.8 & 4.4 & 71.8 & 4.8 \\
\hline
\end{tabular}

$T_{m}^{P E G}, T_{C}^{P E G}=$ melting and crystallization temperatures of $P E G$.

$\Delta H_{m}^{P E G}, \Delta H_{c}^{P E G}=$ melting and crystallization enthalpy values of $P E G$.

$T_{m}^{A}, T_{c}^{A}=$ melting and crystallization temperatures of thermoplastic starch.

$\Delta H_{m}^{A}, \Delta H_{c}^{A}=$ melting and crystallization enthalpy values of thermoplastic starch.

while the most important results are collected in Table 4. The DSC thermogram of the neat starch (A) was not reported here for the sake of brevity, but this test was performed as a preliminary experiment to find a suitable hot-pressing temperature of the laminates (however, the results of this test are reported in Table 4). The thermogram of the neat beech (F) shows a broad endothermic peak on the heating scan that is not present in the cooling and second heating scans. This peak, associated with water evaporation, has an enthalpy of $161.5 \mathrm{~J} / \mathrm{g}$. Considering that the latent evaporation heat of water is $2,272 \mathrm{~J} / \mathrm{g}$, the water present in the neat beech can be estimated at $\sim 7.1 \mathrm{wt} \%$, which is in good agreement with the mass losses observed by TGA in the low temperature region. The other DSC signals of this sample, such as those associated with the glass transitions of the amorphous wood components, are not clearly visible in this plot, but they have been thoroughly described in a recent work of our group on wood/starch composite laminates (Dorigato et al., 2018a). The signal of water evaporation is partially visible also in the first heating scan on the sample FP, which also presents the signals of the melting and crystallization transitions of PEG, through the presence of narrow peaks at 55 and $25^{\circ} \mathrm{C}$, respectively. The phase change enthalpy measured in the first heating scan is $88.5 \mathrm{~J} / \mathrm{g}$. Assuming that the phase change performance and the crystallization behavior of the PEG embedded in the wood are not different from those of the virgin PEG, the total PEG weight fraction in the sample FP can be calculated from the phase change enthalpy of the neat PEG $(169 \mathrm{~J} / \mathrm{g})$, with the result being $52.4 \mathrm{wt} \%$, in good agreement with the nominal PEG content (see Table 2). The peak of water evaporation is also present in the thermograms of the two prepared laminates. The sample FA also clearly shows all the thermal transitions of the starch phase, which are visible in the second heating scan, i.e., a glass transition at $\sim 60^{\circ} \mathrm{C}$, post-crystallization at $110^{\circ} \mathrm{C}$ and a melting peak at $168^{\circ} \mathrm{C}$. The thermal transitions of the starch phase are also visible in the thermogram of the sample LAM (except for the post-crystallization in the second heating scan), although the most intense signal is represented by the phase change transitions of the PEG, whose enthalpy is $27.4 \mathrm{~J} / \mathrm{g}$ (first heating scan). From this signal, the effective PEG weight fraction in the LAM is $16.2 \mathrm{wt} \%$, slightly higher than that calculated from the masses of the laminates, but in the same order of magnitude. This DSC signal clearly demonstrates that the prepared composites could be potentially applied for TES applications.

Figures 5A,B, 6A,B report the thermograms obtained from DMA on the tested materials, performed to investigate their viscoelastic response below and above the PCM melting temperature. Figures 5A,B show the thermograms of the samples A, F, and FP. The latter two samples have been tested with the wood fibers oriented parallel (L) and perpendicular (T) to the applied load. The thermogram of the neat starch (A) has been reported together with the samples in the $T$ directions (for a better comprehension of the plots). The starch phase (A) exhibits a storage modulus at $0^{\circ} \mathrm{C}$ of $\sim 250 \mathrm{MPa}$, and it shows a considerable drop at $\sim 60^{\circ} \mathrm{C}$ in correspondence of the glass transition, in good agreement with the DSC results. The same phenomenon is detectable through peaks in the $\mathrm{E}^{\prime \prime}$ and $\tan \delta$ thermograms. For the neat wood lamina $(F)$, the value of $E^{\prime}$ in the $\mathrm{L}$ direction is one order of magnitude higher than that in the $\mathrm{T}$ direction, and in both cases it shows a slight decrease at $\sim 50^{\circ} \mathrm{C}$ because of the amorphous fraction in the wood (i.e., lignin) (Kelley et al., 1987). From a comparison between the signals of the neat wood (F) and the PEG-impregnated wood (FP) laminae, it is immediately evident that the presence of PEG significantly contributes to increase the storage modulus of the wood laminae in both directions, probably due to a partial filling of the wood porosity. The major signals in the FP thermograms are those related to the PEG phase transition, as $\mathrm{E}^{\prime}$ shows a step, while peaks are visible in both the $\mathrm{E}^{\prime \prime}$ and $\tan \delta$ signals, which are evident mostly in the L direction (Figure 5A). The positive contribution of PEG in increasing $\mathrm{E}^{\prime}$ is also transferred to the laminates (Figures 6A,B), even though this is accomplished to a lesser extent. Also in this case, the thermograms present all the signals related to the thermal transitions of the PEG and starch phases. For example, the PEG melting is clearly detectable through the DMA thermograms. This effect, which evidences the interesting and unusual possibility to study a melting event through DMA, was also observed by our group in other works related to polymer matrix composites containing a PCM (Fredi et al., 2017, 2018a). Further efforts will be performed in the future to better characterize the PCM melting signals through DMA analysis.

Finally, two tests were performed to investigate the effect of PEG on the mechanical properties of the wood laminae and of 


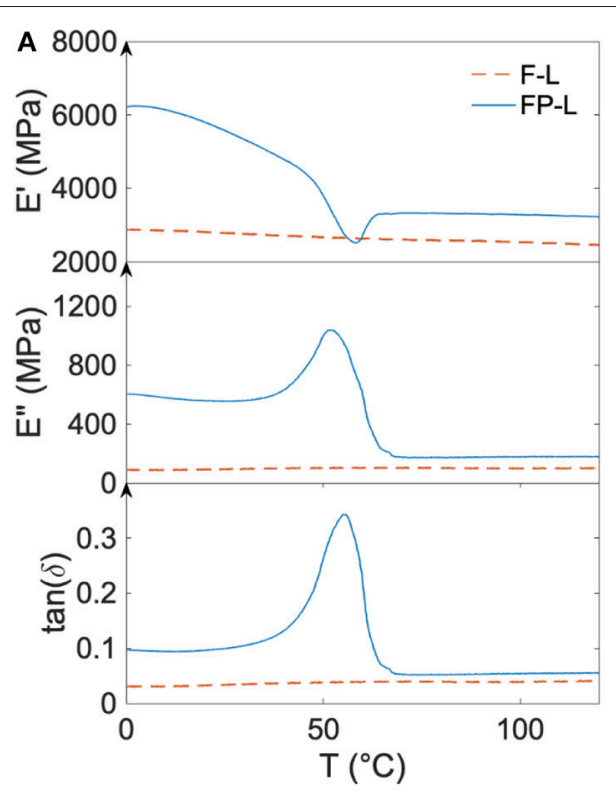

B

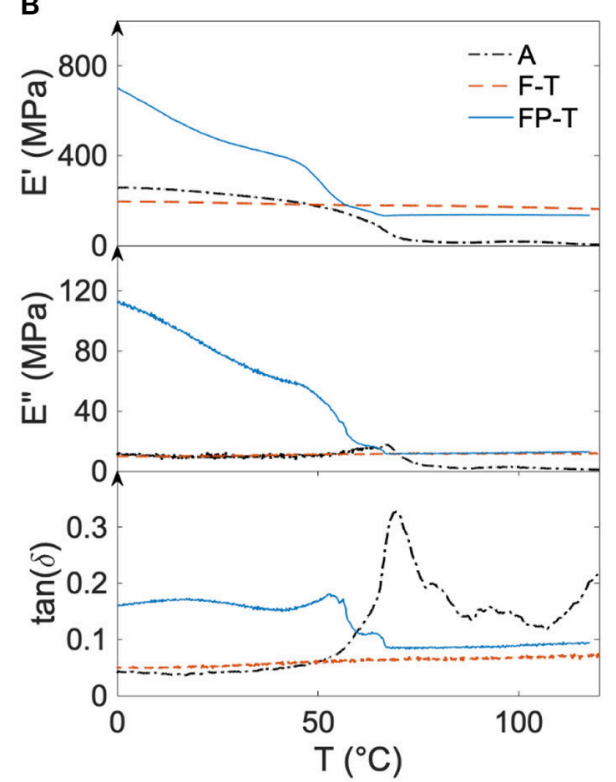

FIGURE 5 | DMA thermograms of the constituents, showing the storage modulus $E^{\prime}$, the loss modulus $E^{\prime \prime}$, and the loss factor tan $\delta$. (A) Samples $F$ and FP (longitudinal direction); (B) samples F, FP (transversal direction), and A.

the relative laminates, i.e., quasi-static tensile tests and Charpy impact tests. For the tensile tests, representative stress-strain curves of the sample FA in all the three considered directions are reported in Figure 7 (the curves for the other samples are not reported for the sake of brevity), while Figure 8 shows the trends of the elastic modulus and of the tensile strength, respectively. The sample $\mathrm{F}$ has a linear stress-strain curve until failure in both the $\mathrm{L}$ and $\mathrm{T}$ directions, with a rather low strain at break $(\sim 1 \%)$. PEG-impregnated laminae (FP) show an initial linear behavior, followed by a region in which the slope decreases until failure. This test also evidences the positive contribution

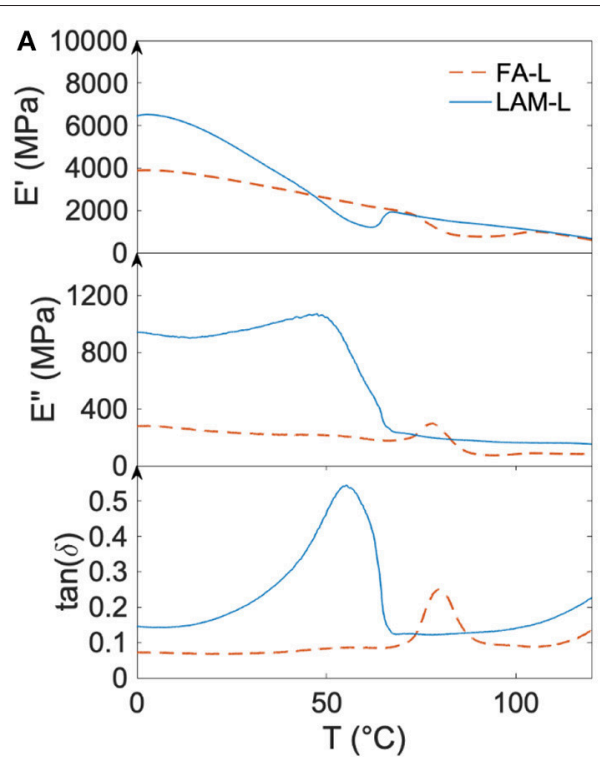

B

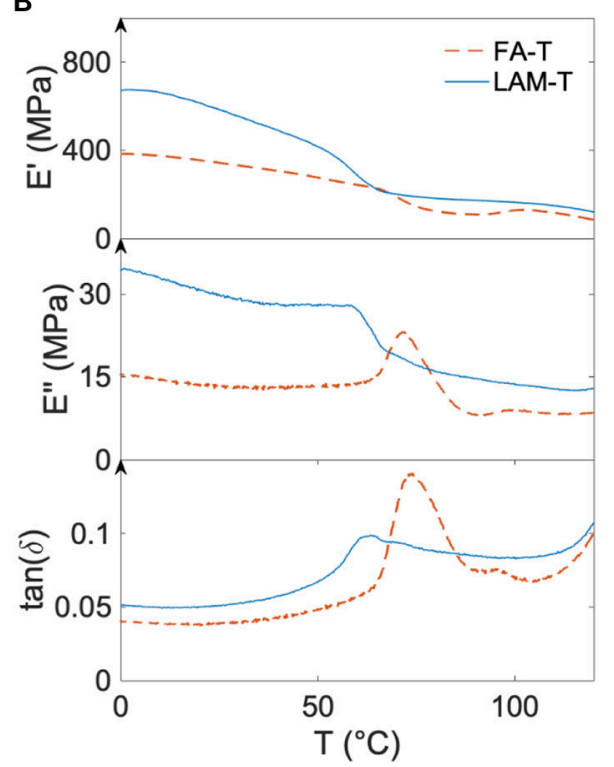

FIGURE 6 | DMA thermograms of the laminates, showing the storage modulus ( $\left.E^{\prime}\right)$, the loss modulus (E"), and the loss factor (tan $\left.\delta\right)$. (A) Samples FA and LAM (longitudinal direction); (B) samples FA and LAM (transversal direction).

of PEG on the tensile properties of the wood laminae, especially in the $\mathrm{T}$ direction, as the average elastic modulus increases from 120 to $310 \mathrm{MPa}$ and the tensile strength from 60 to 170 $\mathrm{MPa}$, while the properties in the L direction of the two samples are not significantly different from each other. The mechanical properties measured on these thin laminae are remarkably lower than those reported for bulk beech, which exhibits a flexural elastic modulus of $14.5 \mathrm{GPa}$ and a flexural strength of 120 MPa (Giordano, 1981). This effect, already observed in previous works of our group (Dorigato et al., 2018b), is attributable to the considerable destroying of the pristine cellular morphology 


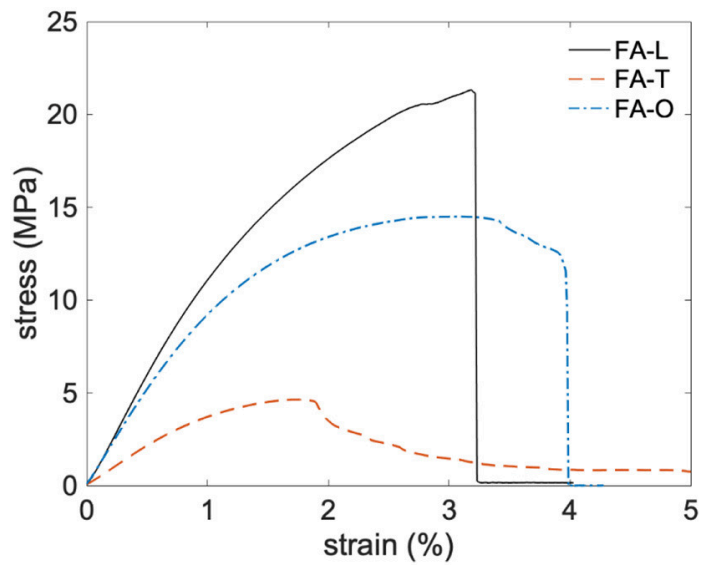

FIGURE 7 | Representative stress-strain curves from quasi-static tensile tests of the sample FA (all the three considered directions).

to which the ultrathin laminae are subjected during cutting. The stress-strain curve of A is typical of a thermoplastic, highly ductile polymer; the initial linear region terminates with a relative maximum, conventionally regarded as the yield point, followed by a strain-hardening region until failure, which happens at high strain values (i.e., 450\%). The properties measured on this starch film are consistent with those reported in the literature for similar materials (Bastioli, 1997; Mark, 1999). From Figure 7 it is immediate to observe that, as expected, the mechanical properties of the angle ply $(\mathrm{O})$ laminates are intermediate in respect to those of the samples L and T. From the results reported in Figure 8, it is also evident that the properties measured on the laminates are considerably higher than those expected from the traditional rule of mixture, largely used to predict the performance of composites. This effect, already observed in previous works (Dorigato et al., 2018a; Fredi et al., 2018b), stems from the partial filling of the wood porosity by the interpenetrated matrix, which reduces the total pore volume fraction. As reported before for the single laminae, this porosity filling effect is also the reason of the enhanced tensile stiffness and strength of the sample LAM compared to FA, in all the considered directions. Considering the elastic modulus results reported in Figure 8, it should be pointed out that the laminates (i.e., FA and LAM) and the constituents (i.e., FP, F, and A) were not tested at the same speed. However, elastic modulus results of the laminates and of their constituents could be directly compared, at least from a qualitative point of view. It must also be considered that the most important comparison in the mechanical properties should be performed between the FA and LAM samples in different orientations, which were tested at the same speed.

Similar conclusions can be drawn by analyzing the results of the Charpy impact tests, summarized in Table 5 (representative force-time curves were not reported for the sake of brevity). The maximum force measured during the test is considerably higher for the LAM samples, and so is the absorbed specific energy, for all the considered fiber orientations. It can be therefore concluded that, contrarily to what has been reported
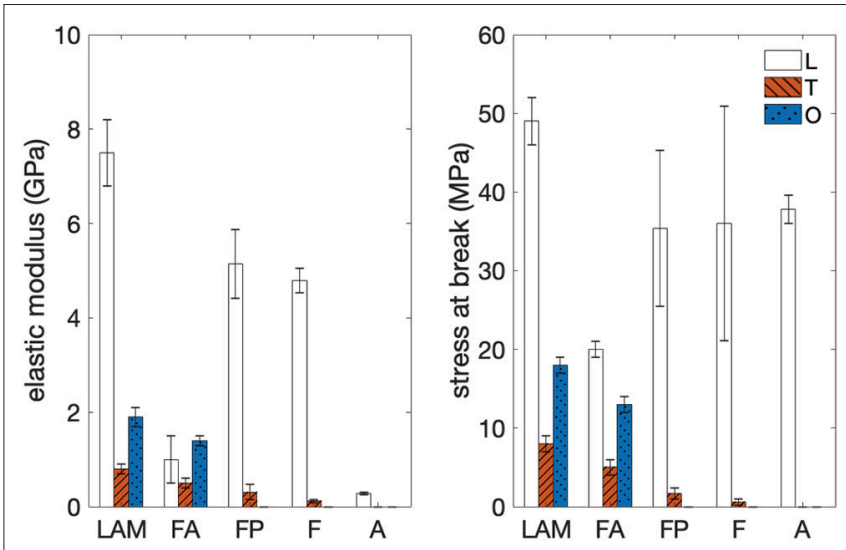

FIGURE 8 | Results of quasi-static tensile tests on the prepared samples. Elastic modulus and stress at break.

TABLE 5 | Results of Charpy impact tests on the two prepared laminates, performed in different orientations.

\begin{tabular}{lcc}
\hline Sample & $\mathbf{F}_{\mathbf{b}}(\mathbf{N})$ & $\mathbf{U}_{\mathbf{s p}}\left(\mathbf{J} / \mathbf{m}^{\mathbf{2}}\right)$ \\
\hline FA-L & 24 & 1.2 \\
FA-T & 11 & 0.6 \\
FA-O & 18 & 1.0 \\
LAM-L & 138 & 23.7 \\
LAM-T & 52 & 7.5 \\
LAM-O & 95 & 14.8 \\
\hline
\end{tabular}

$F_{b}=$ maximum value of force reached during the test.

$U_{s p}=$ specific energy absorbed under impact conditions.

up to now by our group for PCM-containing polymer composites (Fredi et al., 2017, 2018a), in this case the PCM contributes positively to the mechanical properties of the host composite, and the mechanical and TES properties can be considered as synergistic and not parasitic. This is remarkably important in the perspective of developing multifunctional materials combining structural and thermal management functions.

\section{CONCLUSIONS}

This work aimed at developing novel multifunctional fully biodegradable composite laminates with thermal energy storage/release capability. With this aim, thin wood beech laminates were impregnated with PEG at the molten state, and the resulting reinforcements were interleaved to foils of thermoplastic starch through hot compaction. The microstructural and thermo-mechanical behavior of the resulting laminates was thoroughly investigated and compared with that of the relative constituents.

Even though not all the PEG introduced in the samples is effectively confined within the wood pores, a PEG fraction of about $11 \mathrm{wt} \%$ of the whole laminate remained entrapped within wood laminae. From SEM micrographs it was found that PEG is able to partially fill the wood porosity, but 
the presence of PEG on the surface of wood laminae could negatively affect the adhesion and the compenetration between the wood laminae and the starch matrix, thereby worsening the delamination resistance of the resulting composites. From DSC tests it was evident that the stabilization of PEG within the wood pores was responsible for the presence of an endothermic signal at $55^{\circ} \mathrm{C}$, with a specific melting enthalpy of $27.4 \mathrm{~J} / \mathrm{g}$. DMA analysis revealed that the presence of PEG significantly contributed to increasing the dynamic moduli of the laminates because of the partial filling of the wood porosity. For the same reason, the quasi-static properties (stiffness and strength) measured on the laminates were considerably higher than those expected from the traditional rule of mixture, and Charpy tests also showed that the impact resistance of the composites was systematically higher than that of their constituents and of the neat wood/starch laminate.

\section{REFERENCES}

Alexandre, B., Langevin, D., Mederic, P., Aubry, T., Couderc, H., Nguyen, Q. T., et al. (2009). Water barrier properties of polyamide $12 /$ montmorillonite nanocomposite membranes: structure and volume fraction effects. J. Memb. Sci. 328, 186-204. doi: 10.1016/j.memsci.2008.12.004

Averous, L., Fauconnier, N., Moro, L., and Fringant, C. (2000). Blends of thermoplastic starch and polyesteramide: processing and properties. J. Appl. Polym. Sci. 76, 1117-1128. doi: 10.1002/(SICI)10974628(20000516)76:7<1117::AID-APP16>3.0.CO;2-W

Ayucitra, A. (2012). Preparation and characterisation of acetylated corn starches. Int. J. Chem. Eng. Appl. 3, 156-159. doi: 10.7763/IJCEA.2012.V3.178

Bastioli, C. (1997). Properties and applications of Mater-Bi starch-based materials. Polym. Degrad. Stab. 59, 263-272. doi: 10.1016/S0141-3910(97)00156-0

Bledzki, A., Sperber, V., and Faruk, O. (2002). Natural and Wood Fibre Reinforcements in Polymers. Schrewsbury: Rapra Technology Limited.

Bogracheva, T. Y., Wang, Y. L., Wang, T. L., and Hedley, C. L. (2002). Structural studies of starches with different water contents. Biopolymers. 64, 268-281. doi: 10.1002/bip.10190

Chi, H., Xu, K., Wua, X., Chen, Q., Xue, D., Song, C., et al. (2008). Effect of acetylation on the properties of corn starch. Food Chem. 106, 923-928. doi: 10.1016/j.foodchem.2007.07.002

Core, H. A., Coté, W. A., and Day, A. C. (1979). Wood: Structure and Identification. 2nd Edn. Syracuse, NY: Syracuse University Press.

Dorigato, A., Ciampolillo, M. V., Cataldi, A., Bersani, M., and Pegoretti, A. (2017). Polyethylene wax/EPDM blends as shape-stabilized phase change materials for thermal energy storage. Rubber Chem. Technol. 90, 575-584. doi: $10.5254 /$ rct.82.83719

Dorigato, A., Fredi, G., and Pegoretti, A. (2018c). "Novel phase change materials using thermoplastic composites," in 9th International Conference on Times of Polymers and Composites, AIP Conference Proceedings, 020044-1-020044-4. doi: 10.1063/1.5045906

Dorigato, A., Fredi, G., and Pegoretti, A. (2019). Application of the thermal energy storage concept to novel epoxy/short carbon fiber composites. J. Appl. Pol. Sci. 136:47434. doi: 10.1002/APP.47434

Dorigato, A., Negri, M., and Pegoretti, A. (2018a). Ultrathin wood laminaethermoplastic starch biodegradable composites. J. Renew. Mater. 6, 493-503. doi: 10.7569/JRM.2017.634177

Dorigato, A., Negri, M., and Pegoretti, A. (2018b). Ultrathin wood laminaepolyvinyl alcohol biodegradable composites. Polym. Compos. 39, 1116-1124. doi: $10.1002 /$ pc. 24040

Dorigato, A., and Pegoretti, A. (2012). Biodegradable single polymer composites from polyvinylalcohol. Colloid Polym. Sci. 290, 359-370. doi: 10.1007/s00396-011-2556-Z
This work demonstrated the possibility to prepare fully biodegradable multifunctional materials by combining structural and thermal management functions, in which the insertion of a biodegradable PCM had a positive effect on the mechanical performance of the host composite.

\section{AUTHOR CONTRIBUTIONS}

$\mathrm{AD}$ performed part of the experimental work and performed the editing of the manuscript. GF performed part of the experimental work and performed the editing of the manuscript. AP coordinated the editing of the manuscript.

\section{ACKNOWLEDGMENTS}

Mr. Federico Vespa is gratefully acknowledged for his support to the experimental work.

Fredi, G., Dorigato, A., Artuso, N., and Pegoretti, A. (2019). Discontinuous carbon fiber/polyamide composites with microencapsulated paraffin for thermal energy storage. J. Appl. Polym. Sci. 136:47408. doi: 10.1002/app.47408

Fredi, G., Dorigato, A., Fambri, L., and Pegoretti, A. (2017). Wax confinement with carbon nanotubes for phase changing epoxy blends. Polymers. 9, 405-420. doi: 10.3390/polym9090405

Fredi, G., Dorigato, A., Fambri, L., and Pegoretti, A. (2018a). Multifunctional epoxy/carbon fiber laminates for thermal energy storage and release. Compos. Sci. Technol. 158, 101-111. doi: 10.1016/j.compscitech.2018. 02.005 .

Fredi, G., Dorigato, A., and Pegoretti, A. (2018b). Multifunctional glass fiber/polyamide composites with thermal energy storage/release capability. Express Polym. Lett. 12, 349-364. doi: 10.3144/expresspolymlett.2018.30

Fredi, G., Dorigato, A., and Pegoretti, A. (2019). Novel reactive thermoplastic resin as a matrix for laminates containing phase change microcapsules. Pol. Compos. doi: $10.1002 / p c .25233$

García, M., Garmendia, I., and García, J. (2008). Influence of natural fiber type in eco-composites. J. Appl. Polym. Sci. 107, 2994-3004. doi: 10.1002/app.27519

Gay, D., Hoa, S. V., and Tsai, S. W. (2003). Composite Materials. Design and Applications. Boca Raton, FL: CRC Press.

Gibson, R. F. (2010). A review of recent research on mechanics of multifunctional composite materials and structures. Compos. Struct. 92, 2793-2810. doi: 10.1016/j.compstruct.2010.05.003

Giordano, G. (1981). Tecnologia del legno. La materia prima. Vol. 1. Torino: UTET.

Green, D. W., Winandy, J. E., and Kretschmann, D. E. (1999). "Mechanical properties of wood," in Wood Handbook-Wood as an Engineering Material, ed. F. P. Laboratory (Madison, WI: U.S. Department of Agriculture, Forest Service, Forest Products Laboratory).

Houshyar, S., and Shanks, R. A. (2003). Morphology, thermal and mechanical properties of poly(propylene) fibre-matrix composites. Macromol. Mater. Eng. 288, 599-606. doi: 10.1002/mame.200300023

Iwatake, A., Nogi, M., and Yano, H. (2008). Cellulose nanofiberreinforced polylactic acid. Compos. Sci. Technol. 68, 2103-2106. doi: 10.1016/j.compscitech.2008.03.006

Kastiukas, G., Zhou, X. M., and Castro-Gomes, J. (2016). Development and optimisation of phase change material-impregnated lightweight aggregates for geopolymer composites made from aluminosilicate rich mud and milled glass powder. Constr. Build. Mater. 110, 201-210. doi: 10.1016/j.conbuildmat.2016.02.029

Kelley, S. S., Rials, T. G., and Glasser, W. G. (1987). Relaxation behaviour of the amorphous components of wood. J. Mater. Sci. 22, 617-624. doi: 10.1007/BF01160778

Khadiran, T., Hussein, M. Z., Zainal, Z., and Rusli, R. (2015). Encapsulation techniques for organic phase change materials as thermal energy 
storage medium: a review. Solar Energy Mater. Solar Cells. 143, 78-98. doi: 10.1016/j.solmat.2015.06.039

Kou, Y., Wang, S., Luo, J., Sun, K., Zhang, J., Tan, Z., et al. (2019). Thermal analysis and heat capacity study of polyethylene glycol (PEG) phase change materials for thermal energy storage applications. J. Chem. Thermodyn. 128, 259-274. doi: 10.1016/j.jct.2018.08.031

Kunanopparat, T., Menut, P., Morel, M., and Guilbert, S. (2008). Reinforcement of plasticized wheat gluten with natural fibers: from mechanical improvement to deplasticizing effect. Compos. Appl. Sci. Manufac. 39, 777-785. doi: 10.1016/j.compositesa.2008.02.001

Lorcks, J. (1998). Properties and applications of compostable starch-based plastic material. Polym. Degrad. Stab. 59, 245-249. doi: 10.1016/S0141-3910(97)00168-7

Luyt, A. S., and Krupa, I. (2009). Phase change materials formed by uv curable epoxy matrix and Fischer-Tropsch paraffin wax. Energy Conv. Manage. 50, 57-61. doi: 10.1016/j.enconman.2008.08.026

Mallick, P. K. (2007). Fiber Reinforced Composites. Materials, Manufacturing, and Design. Boca Raton, FL: Taylor \& Francis Group, LLC.

Mark, J. E. (1999). Polymer Data Handbook. Oxford: Oxford University Press.

Oksman, K., and Sain, M. (2008). Wood-Polymer Composites. Cambridge: Woodhead Publishing Materials.

Onder, E., Sarier, N., and Cimen, E. (2008). Encapsulation of phase change materials by complex coacervation to improve thermal performances of woven fabrics. Thermochim. Acta. 467, 63-72. doi: 10.1007/s12221-016-5113-Z

Ozaki, T., Takeya, H., Kume, M., and Sekine, K. (2008). Multifunctional composite structures for space satellites. Sampe J. 44, 6-11.

Pegoretti, A. (2007). Trends in composite materials: the challenge of single-polymer composites. Express Polym. Lett. 1, 710. doi: 10.3144/expresspolymlett.2007.97

Pielichowska, K., and Pielichowski, K. (2014). Phase change materials for thermal energy storage. Prog. Mater. Sci. 65, 67. doi: 10.1016/j.pmatsci.2014.03.005

Rigotti, D., Dorigato, A., and Pegoretti, A. (2018). 3D printable thermoplastic polyurethane blends with thermal energy storage/release capabilities. Mater. Today Commun. 15, 228-235. doi: 10.1016/j.mtcomm.2018.03.009

Salonitis, K., Pandremenos, J., Paralikas, J., and Chryssolouris, G. (2010). Multifunctional materials: engineering applications and processing challenges. Int. J. Adv. Manufac. Technol. 49:803. doi: 10.1007/s00170-0092428-6

Sari, A., Akcay, M., Soylak, M., and Onal, A. (2005). Polymer-stearic acid blends as form-stable phase change material for thermal energy storage. J. Sci. Ind. Res. 64, 991-996. Available online at: http://hdl.handle.net/123456789/5380

Sobolciak, P., Karkri, M., Al-Maaded, M. A., and Krupa, I. (2016). Thermal characterization of phase change materials based on linear low-density polyethylene, paraffin wax and expanded graphite. Renew. Energy. 88:372 doi: 10.1016/j.renene.2015.11.056

Srimalanon, P., Yamsaengsung, W., Kositchaiyong, A., Wimolmala, E., Isarangkura, K., and Sombatsompop, N. (2016). Effects of UV-accelerated weathering and natural weathering conditions on anti-fungal efficacy of wood/PVC composites doped with propylene glycol-based HPQM. Express Polym. Lett. 10, 289-301. doi: 10.3144/expresspolymlett.2016.27

Sundararajan, S., Samui, A. B., and Kulkarni, P. S. (2016). Interpenetrating phase change polymer networks based on crosslinked polyethylene glycol and poly(hydroxylethyl methacrylate). Solar Energy Mater. Solar Cells. 149, 266-274. doi: 10.1016/j.solmat.2015.12.040

Wang, J. J., Yang, M., Lu, Y. F., Jin, Z. K., Tan, L., Gao, H. Y., et al. (2016). Surface functionalization engineering driven crystallization behavior of polyethylene glycol confined in mesoporous silica for shape-stabilized phase change materials. Nano Energy. 19, 78-87. doi: 10.1016/j.nanoen.2015.11.001

$\mathrm{Wu}$, C.-S. (2009). Renewable resource-based composites of recycled natural fibers and maleated polylactide bioplastic: characterization and biodegradability. Polym. Degrad. Stab. 94, 1076-1084. doi: 10.1016/j.polymdegradstab.2009.04.002

Yang, J., Zhang, E., Li, X., Zhang, Y., Qu, J., and Yu, Z. (2016). Cellulose/graphene aerogel supported phase change composites with high thermal conductivity and good shape stability for thermal energy storage. Carbon. 98, 50-57. doi: 10.1016/j.carbon.2015.10.082

Yoo, S., Kandare, E., Shanks, R., Al-Maadeed, M. A., and Afaghi Khatibi, A. (2016). Thermophysical properties of multifunctional glass fibre reinforced polymer composites incorporating phase change materials. Thermochim. Acta. 642, 25-31. doi: 10.1016/j.tca.2016.09.003

Zhou, Y., Sheng, D. K., Liu, X. D., Lin, C. H., Ji, F. C., Dong, L., et al. (2018). Synthesis and properties of crosslinking halloysite nanotubes/polyurethane based solid-solid phase change materials. Sol. Energy Mater. Sol. Cells. 174, 84-93. doi: 10.1016/j.solmat.2017.08.031

Conflict of Interest Statement: The authors declare that the research was conducted in the absence of any commercial or financial relationships that could be construed as a potential conflict of interest.

Copyright (c) 2019 Dorigato, Fredi and Pegoretti. This is an open-access article distributed under the terms of the Creative Commons Attribution License (CC BY). The use, distribution or reproduction in other forums is permitted, provided the original author(s) and the copyright owner(s) are credited and that the original publication in this journal is cited, in accordance with accepted academic practice. No use, distribution or reproduction is permitted which does not comply with these terms. 